\title{
MJN CAPACITY STRENGTHENING AMONG YOUTH TO IMPROVE HEALTH OUTCOME: A REVIEW OF LITERATURE
}

\author{
Kristina Lisum ${ }^{1,3 *}$, Agung Waluyo ${ }^{2}$, Sudibyo Supardi ${ }^{4}$ \\ ${ }^{1}$ Faculty of Nursing, Universitas Indonesia, Indonesia \\ ${ }^{2}$ Faculty of Nursing, Universitas Indonesia, Depok, Indonesia \\ ${ }^{3}$ STIK Sint Carolus, Jakarta, Indonesia \\ ${ }^{4}$ National Institute of Health Research and Development, Indonesia \\ *Corresponding Author's Email: kristinalisum@gmail.com
}

\begin{abstract}
Background: Many countries focus on strengthening the capacities of individual, group and organization including in health care setting. However, most of the capacity strengthening only focuses on increasing the knowledge and skills of all age groups, including the youth. The capacity strengthening delivered by the health care professional needs to be adjusted with the youth growth and development, thus it will increase the youth interpersonal domain. Aim: The aim of this study was to identify the capacity strengthening program for the youth to improve the parents' health behavior. Methods: A literature review was done based on the articles published from search engine such as Clinical Key, Ebscohost with Cinahl and ProQuest from 2003 2021. Results: The strengthening capacity of youth consist of many steps, there are health assessment of targeted population, home visit, parents involving, educational program and monitoring, report, documentation. Conclusion: This review found that intervention using youth act as change agent that improve parents' health behavior especially change in family lifestyle. It is essential that further research is implemented to determine whether youth capacity strengthening is also effective for parents with infectious disease.
\end{abstract}

Keywords: Capacity Strengthening; Youth; Health; Change Agent

\section{INTRODUCTION}

In achieving Sustainable Development Goals, many countries focus on strengthening capacities at individual, groups, organizational and environmental level including in health care setting. However, the practice is commonly seen different from a number of relevant framework where capacity strengthening largely seen as knowledge increase and skills development. Conceptually, capacity strengthening is more than knowledge acquisition. It also includes technical, intrapersonal and interpersonal domains (Finn et al., 2021). The concept of strengthening the capacities in health field is provided, implemented and delivered by the health care professional, such as nurses for the youth age group.

Youth is the nation's next generation who has a lot of potential and energy to develop. In developing countries, youth including $\mathrm{Z}$ and millennial generations covers the largest percentage, including in Indonesia (BPS, 2019). However, youth or younger people are often not involved in maintaining their own health, more over their family. In fact, youth have a desire to become active participants as long as they have appropriate concepts and information, so that their voices can be heard. Youth tends to be discounted of their role as pawn (Larcher et al., 2020). Due to this situation, this study was conducted to discuss the concept of capacity strengthening on the youth.

\section{METHODOLOGY}

A literature search was undertaken of the following electronic databases such as ProQuest, EBSCO Host, CINAHL, Science Direct, and WILEY online Library with the keywords of youth, capacity strengthening, capacity building, and health behavior. The literature search was limited to those which published in 2000 to 2021. 


\section{Review of Literature}

\section{The Concept of Capacity Strengthening}

Most of the capacity strengthening is used as a term of capacity building that came from two words, those are capacity and strengthening or building. Capacity refers to the ability of individual, group or organization, while strengthening or building refers to an action that is set to make something more stronger (Merriam, 2021). So, capacity strengthening is a process that continuously happens in individual, groups, organizations and societies to perform basic role by using its ability to cope with all aspects of their existence and building the capacity to nurture these qualities towards sustainability, solving problems and achieve goals (Fanany, Fanany, \& Kenny, 2003; Horton et al., 2003; CRS, 2021). When health care professional develops capacity strengthening to individual, group or organization, they need to understand about each individual's three level capacities that consist of technical, intrapersonal and interpersonal domain (Finn et al., 2021). The technical level includes knowledge, skills, ability, practice, timeliness, and competencies; interpersonal level includes leadership, resources, communication, conflict resolution, and change management; and intrapersonal level includes confidence, motivation, self-efficacy, commitment, and attitude.

\section{Youth and Capacity Strengthening}

Youth is considered as a group with high risk because they tend to develop risk behaviour such as smoking, violence, drug uses, sex abuse, and free life style, that may lead to death. Besides that, youth often develops difficult situation such as poverty, family dysfunction, and the death of family members/parent (WHO, 2011). Youth has important periods in human growth and development (UU RI no 40, 2009), that might develop positive role. Youth can act as a catalyst in a process of interaction in the family, even in communities Percy-Smith \& Burns, 2012) by advocating family to help provide health information and give support to parents (Toomey et al., 2018; Heinert et al., 2019). In this pandemic situation, the nurses' role in strengthening the youth is important for health development (KMK RI No 279, 2006; Menteri Kesehatan, 2019), such as by educating and taking care of people around them including their parents to prevent the infection of COVID-19, especially when their parents are vulnerable and belong to high risk group
(WHO, 2021).

Youth and families quality of life can be improved by maximizing the existing ecosystem as a support. Canada has used the youth at the age of 15-24 years old as a strategy to change the social aspects including health for more than 35 years from 1978 to 2012 (Ho et al., 2015). For this reason, the development and management of youth's potential in the family and community have a crucial role in the health development process (Toomey et al., 2018). Health care professional must understand about the reason of youth needs and willingness to engage in capacity strengthening (Mukherjee, 2015). Youth participation is not only limited to their social support such as being peer educator for depression and bullying problem (Yin et al., 2017; Zachariah et al., 2018), but youth must participate to take care or maintain their family health behaviour too. When health care professional could not see this opportunity and youth capacity, youth can act passive or felt being excluded.

\section{Capacity Strengthening as a Process}

Assistance and the management of the youth potential, especially in health development, requires consistency in its implementation, especially by health care professional, including nurses. Nurses must see this as a challenge or an opportunity to manage the youth's potential to become the change agent. Capacity strengthening provides set of action/ intervention that must be prepared when giving capacity strengthening to the youth including:

\section{Health Assessment of Targeted Population}

Before implementing the program, health care professional needs to assess the capacity of the youth group when providing a set of intervention. The assessment should be conducted by using the following behaviours: listening and questioning, observing, reviewing records, collaborating with the health care team, and integrating the clients' verbal description with the health care professionals' observation. Through training, health care professional provides steps for the members of youth group in Sri Lanka at the age of 15-29 years old when changing the adults' behaviour to decrease the risk of heart disease. The first step is health assessment. In this phase, youth must collect information about adult life style such as the lack of physical activity, unhealthy diet, smoking, alcohol, 
and poor mental management. Besides that, youth also needs data about adult physical status such as height, weight, and blood pressure that use the electrical sphygmomanometer, after that youth must document it in a report (Chandraratne et al., 2019).

A study was also conducted in school setting where health care professional provides steps to the students with younger age of 13 years old by involving the parents. This study stated that a program that motivates students to act as a change agent in the family life style proved to be effective in weight loss and increased physical activity of a mother in a family. An assessment step was conducted through a discussion about the meaning of health and wellbeing from the mothers' perspective. In this case, the students became encouraged to define and measure the risk factor and share an idea about health and healthy determinants, having group discussion to provide ways influencing their mother (Gunawardena et al., 2016). Assessment is a foundation phase that needs to be built and strengthened when the youth acts to be the change agents improving the family or community health.

\section{Home Visit}

Home visit is considered as an important aspect provided by a health care professional. This aspect provides important and critical attributes. This step gains entry or sees in the forming of a partnership with equal balance or power have participant and health visitor act as a guest. Besides gaining entry, the other critical attributes from home visit is an understanding of the clients health needs as he or she sees it. It means that the health visitor sees problem the way client sees it, has mutual goal setting, an event and a process, shares responsibility, and locus of control on client and education for self-care (Pastor, 2006). Since youth has received capacity strengthening, youth can act also as a home visitor or health visitor. Health care professional needs to provide aspects that need to be delivered during home visit.

Through this study, researcher developed a strategy of home visit with certain goal, such as youth visits area in community to measure the weight, blood pressure with electric sphygmomanometer twice a month, and give recommendation and encouragement about healthy lifestyle such as doing physical activity, reducing high sugar snack foods and fast foods, and reducing the use of cooking oil to change the adults' behaviour (Chandraratne et al., 2019).

\section{Parents Involving}

In school-based intervention, many researches had used youth as change agents to improve parents' health. Youth has a lot of energy to build their capacity which is not only limited to their intrapersonal domain but also they must build their interpersonal domain, especially to family that can bind relationship between them. Research that was conducted by (Gunawardena et al., 2016) placed the trained youth of the age 13 years old to provide feedback to their mother including monitoring their mothers' life style and health status such as body weight, participation in exercise, and sedentary behaviour. Youth is also motivated in creating change in their home. The intervention occurred for 12 months and initial funding was made by the facilitator at the time of intervention, and then reduced to 3-4 weeks, then 5 months per one visit. The primary outcome of this study is the change of baseline during the 12 months after the follow-up, body weight and body mass index, while the secondary outcome is self-report on the level of physical activity and the number of steps taken by the pedometer and a report of number of consumed fruit, vegetables, fried foods, or sweet foods. Besides, the secondary outcomes are also the cost paid per month for buying cooking oil, sugar, biscuits, and ice cream (Gunawardena et al., 2016).

Another study was conducted in China to the young students at the age of 10 years old. The young students gave message to family about reducing salt. This intervention was carried out for about 3 to 5 months. The primary outcome of this study was a change in salt intake as measured by measuring 24-hour urinary sodium excretion, while the secondary outcome of this study was a change in blood pressure between the two groups. The results of the study showed that there was a reduction in salt intake in the intervention group, while in the contiguous group, there was an increase in salt intake with $p<0.001$ in adults, while the decrease in blood pressure was around $4.5-0.04 \mathrm{mmHg}$ in adults with $p<$ 0.005 (He et al., 2015).

\section{Educational Program}

Health professional has the responsibility to become an educator to improve health behaviour through health education. Along with nurses, other members of health care team make significant contribution to the clients' education. Health education is defined as theoretical concepts, effective strategies, and core competencies seeks to provide a common 
understanding of health education and related concept (WHO, 2012). Health care professional must strengthen the youth ability, more over youth ability in this era by helping them identify and socialize their own learning style (Lisum \& Sianturi, 2020). Youth learning style must be strengthened when they precede health information. Through health literacy, youth can seek and engage with the use of health information to enable and access health care activities. When youth has competencies to health literacy and provision from health professional, they could build interactive media that is easier to proceed to targeted population such as family, parents, and community.

Study using school-age youth aged 11-12 years old reported changes in parents' behavior to prevent stroke using stroke education program (Kato et al., 2017). The intervention was carried out on 268 students aged 11-12 years old and 267 parents in Japan. The intervention given was an educational program about strokes in the form of animated cartoons which were conveyed to their parents using comic books. The knowledge about stroke given was in the form of signs and symptoms, risk factors, and also attitudes in dealing with strokes and behavior changes which were evaluated immediately after the program was given for 3 months. In addition, an evaluation of behavioral changes in the occurrence of risk factors of parents was also carried out. The results of this study discovered that there was a change in knowledge, risk factors, and the recommendations given by students and parents for 3 months with $p<0.001$ each. Meanwhile, there was also an increase in the percentage of responses to the risk factor behavior of the parents significantly within 3 months with a $p$ value $<0.001$. This study concluded that in the rural areas with high stroke mortality rate population, the stroke education given can increase the knowledge of the students and parents.

Another study was designed for the age ranges 6-8 years old and 9-10 years old children to improve parents' reduction of cardiovascular risk through educational program held by multidisciplinary discipline. The program about cardiovascular prevention exposed for an hour per week including concepts of healthy nutrition, the importance of a more active life with more physical exercise, and the hazardous effects of smoking using educational films, educational plays, and educational games. In the nutritional activities, children learnt about the nutritional content of several types of foods, prepared notes about the daily consumption of sugar, learned to make and taste healthy juices and sandwiches in practical cooking classes, and talked to the nutritionists about how to make healthy choices. The children and their parents participated in family bike rides and Olympic-style events organized in the school where they had the opportunity to enjoy doing exercise together. The teachers participated actively in the program discussing with the students what they had learnt in the classroom; they promoted a competition of healthy stories, with certificates and medals, where children were encouraged to write and draw stories about healthy habits and how to achieve a healthier life. From this study, it resulted in the reduction of cardiovascular risk using FCR (Framingham cardiovascular risk) of all parents in the average risk in the intervention group with $p<0.001$ ( Fornari et al., 2012). From this study, researcher did not ask children to feel responsible for their family lifestyle modification.

\section{Monitoring, Documentation and Report}

The goal of capacity building or capacity strengthening is to enable individual, groups and organizations to adapt and solve problems to achieve sustainability. However the indicators of monitoring, documentation and report are difficult to develop, because of the uniqueness of the project (Bates et al., 2011). Many indicators used for monitoring and evaluation were based on the requirements of each researcher. In term of youth as agent of change with provision from health professional, report that documented from the youth need to interpret the evaluating family or community health behaviour. By developing the leadership of parents and youth and engaging them in campaigns to improve learning and health condition will help to develop health resources into the neighbourhoods (Flores, Goeke \& Perez, 2014).

\section{DISCUSSION}

Nurses as health professional must carry out strategy to build and strengthen the youth capacity. The program or the project for capacity strengthening is not only limited to the educational program, but also involving three levels of capacities for each individual. Youth are not only the objects that are always highlighted as trouble maker, but by involving them as an actor to change parents' health behavior or as advocate role, youth have the potential to identify the health behaviors, as well as formulate and do some strategies based action, and it can generate substantial impact not only for themselves, but also to their communities (Toomey et 
al., 2018), including family. Youth capacity building could be delivered through training, developing youth-adult partnership, improving knowledge, skills or practice and behavior (Millstein \& Sallis, 2011; Ferrari, 2018). Health professional also should utilize the emerging technology to increase awareness and reduce misconception about health information or relevant issues by developing the technology information along the era of development. Therefore, a better healthcare development will be achieved and will prepare them in taking action to meet the health national development. Nurses play an important role to assist, manage, support, and work with the youth so that it can optimize a better health and education outcome.

\section{CONCLUSION}

Youth with various kinds of health problems, can also act as an agent for change to improve the adult health behavior in the smallest scope, namely family. Youth still needs assistance and consistent involvement of trained facilitators or health professional in providing intervention strategies, so that youth has an impact on the occurrence of behavior changes mentioned above. When improving the adult health behavior, health care professional helps to build and strengthen the youth three domain capacities as a way to achieve outcomes. Changes in health behavior as an outcome of research reviewed were to prevent disease caused by the unhealthy living. Facilitators or competent health professional need to provide a strengthening or building an effort to youth and younger people so that these young people are more recognized and involved in providing roles in health development. It is essential that further research is implemented to determine youth empowerment as the most effective actors for parents with infectious disease.

\section{Conflict of Interests}

The authors declare that they have no conflict of interest.

\section{ACKNOWLEDGEMENT}

The authors are thankful to the institutional of authority for completion of this work.

\section{REFERENCES}

Bates, I., Taegtmeye, M., Squire, S.B., Ansong, D., Simwaka, B.N., Baba, A., \& Theobald, S. (2011). Indicators of sustainable capacity building for health research : analysis of four African case studies. Health Research Policy and Systems, 9(14), 1-9.

BPS (2019) Statistik Pemuda Indonesia. DKI Jakarta. Retrived from: https://jakarta.bps.go.id/publication/2020/ 12/28/77d4c8a155c6f63f0588b502/statistik-pemuda-provinsi-dki-jakarta-2019.html

Chandraratne, N., Yamaguchi, M., Indrawansa, S., Gunawardena, N., Kuwahara, K., Islam, Z., Kawasaki, Y., Mizoue, T., \& Samarasinghe, D. (2019). The effect of youths as change agents on cardiovaskular diseases risk factors among adult neighbours : a cluster randomised controlled trial in Srilanka. BMC Public Health, 19(893), 1-11. doi:10.1186/s12889-019-7142-1.

CRS (2021) Partnership \& Capacity Strengthening. Retrieved from: https://www.crs.org/our-work-overseas/ program-areas/partnership-and-capacity-strengthening

Fanany, I., Fanany, R., \& Kenny, S. (2003). The meaning of capacity building in Indonesia', Community Development Journal, 1, 89-103.

Ferrari, T. M. (2018). YA4-H! Youth Advocates for Health: Youth Participatory Action Research. Journal of Youth Development, 13(3), 264-271. doi: 10.5195/jyd.2018.653.

Finn, M., Gilmore, B., Sheaf, G., \& Vallières, F. (2021). What do we mean by individual capacity strengthening for primary health care in low-and middle-income countries? A systematic scoping review to improve conceptual clarity. Human Resources for Health, 19(1), 1-13.

Flores, G., Goeke M.L., \& Perez, R. (2014). The Power of Youth in Improving Community Conditions for Health., NAM 
Perspectives. Washington DC. doi:10.31478/201409b.

Fornari, L.S., Giuliano, I., Azvedo, F., Pastana, A., Vieira, C., \& Caramelli, B. (2012). Children First Study: How an educational program in cardiovascular prevention at school can improve parents' cardiovascular risk. European Journal of Preventive Cardiology, 20(2),301-309. doi:10.1177/2047487312437617.

Gunawardena, N., Kurotani, K., Indrawansa, S., Nonaka, D., Mizoue, T., \& Samarasinghe, D. (2016). School-based intervention to enable school children to act as change agents of weight, physical activity and diet of their mothers : a cluster randomized controlled trial. International Journal of Behavioral Nutrition and Physical Activity, 13(45). doi: 10.1186/s12966-016-0369-7.

He, F.J., Wu, Y., Feng, X., Ma, J., Wang, H., Zhang, J., Yuan, J., Lin, C., Nowson., C., \& MacGregor, G. (2015). School based education programme to reduce salt intake in children and their families (School-EduSalt): Cluster randomise): cluster randomised controlled trial. The BMJ,350(h770). doi: 10.1136/bmj.h770.

Heinert, S., Kowalski, S., Quasim, N., Suarez, N., \& Hock, T. (2019). Empowering Chicago's Youth as the Next Generation of health Advocates. AJPH Practice, 109(7), 1025-1027.

Ho, E., Clarke, A., \& Dougherty, I. (2015). Youth-led social change : Topics, engagement types, organizational types, strategies, and impacts. Future, 67, 52-62. doi: 10.1016/j.futures.2015.01.006.

Horton, D., Alexaki, A., Lartey, S., Brice, K.N., Campilan, D., Carden, F., Silva, J., Duong, L., Khadar, I., Boza, A., Muniruzzaman, I., Perez, J., Chang, M., Vernooy, R., \& Watts, J. (2003). Evaluating Capacity Development: Experiences from Research and Development Organizations around the World. $4^{\text {th }}$ edn, add International Service for National Agricultural Research (ISNAR), the Netherlands; International Development Research Centre (1DRC), Canada; and ACP-EU Technical Centre for Agricultural and Rural Cooperation (CTA), the Netherlands International. 4th edition. ISNAR, IDRC, CTA.

Kato, S., Okamura, T., Kuwabara., K., Takekawa, H., Nagao, M., Umesawa, M., Sugiyama, D., Miyamatsu, N., Hino, T., Wada, S., Arimizu, T., Takebayashi, T., Kobashi, G., Hirata, K., Yokota, C., \& Minematsu, K. (2017). Effects of a school-based stroke education program on stroke-related knowledge and behaviour modification-school class based intervention study for elementary school students and parental guardians in a Japanese rural area. BMJ Open, 7. doi: 10.1136/bmjopen-2017-017632.

KMK Republik Indonesia No 279 (2006).

Larcher, V., Dittborn, M., Linthicum, J., Sutton, A., Brierley, J., Payne, C., \& Hardy, H. (2020). Young people's views on their role in the COVID-19 pandemic and society's recovery from it. Archives of Disease in Childhood, 105(12), 1192-1196. doi:10.1136/archdischild-2020-320040.

Lisum, K., \& Sianturi, S. R. (2020). Nursing Students' Perception of Their Learning Style. Journal Keperawatan, 11(2). doi: 10.22219/jk.v11i2.12478.

Menteri Kesehatan (2019). 'PMK No 8'.

Merriam, W. (2021). Capacity. Retrieved from: https://www.merriam-webster.com/dictionary/capacity (Accessed: 12 March 2021).

Millstein, R. A., \& Sallis, J. F. (2011). Youth advocacy for obesity prevention: The next wave of social change for health. Translational Behavioral Medicine, 1(3), 497-505. doi: 10.1007/s13142-011-0060-0.

Mukherjee, A. S. (2015). Capacity Strengthening within a developmental context : Developing and Appying a Conceptuaal Model. EJISDC, 70(6), 1-22. doi: 10.1002/j.1681-4835.2015.tb00506.x.

Pastor, D. K. D. (2006). Home Sweet Home : A Concept Analysis of Home Visiting. Home Healthcare Nurse, 24(6), 389-394. doi: 10.1097/00004045-200606000-00011. 
Percy-Smith, B., \& Burns, D. (2013). Exploring the role of children and young people as agents of change in sustainable community development. Local Environment, 18(3), 323-339.

Toomey, M., Smathers, C., Iaccopucci, A., Johnston, K., \& Johannes, E. (2018). Youth Workers' Role in Engaging Youth in Health Advocay for Community-Level Change. Journal of Youth Development, 13(3), 12-23. doi:10.5195/jyd.2018.668.

Undang Undang Republik Indonesia No 40 (2009). Indonesia. Retrieved from: https://www.dpr.go.id/ dokjdih/document/uu/UU_2009_40.pdf

World Health Organization (WHO) (2012). Regional Office for the Eastern Mediterranean. Health Education: Theoritical Concepts, Effective Strategies and Core Competencies: a Foundation Document to Guide Cacity Development of Health Educatore. Retrieved from: https://apps. who.int/iris/handle/10665/119953.

World Health Organization (WHO) (2011). Youth and health risks Report from Sixty-Fourth World Health Assembly. Who(April), 1-7.

World Health Organization (WHO) (2021) COVID 19 : Vurnerable and High Risk Groups. Retrieved from: https:// www.who.int/westernpacific/emergencies/covid-19/information/high-risk-groups

Yin, X., Wang, L., Zhang, G., Liang, X., Li, J., Zimmerman, M., \& Wang, J. (2017). The promotive effects of peer support and active coping on the relationship between bullying victimization and depression among chinese boarding students. Psychiatry Research, 256(2), 59-65. doi: 10.1016/j.psychres.2017.06.037.

Zachariah, B., De Witt, E., Bahirat, J., Aelen, J., \& Regeer, B. (2018). What is in It for Them? Understanding the Impact of a "Support, Appreciate, Listen Team" (SALT)-Based Suicide Prevention Peer Education Program on Peer Educators. School Mental Health, 10(4), 462-476. doi: 10.1007/s12310-018-9264-5. 